\title{
The trend of sharenting among Malaysian parents: a qualitative study on their content and motivation
}

\author{
Lee Jia Wen ${ }^{1}$, Crendy Tan Yen Teng ${ }^{2}$, Saroja Dhanapal ${ }^{3}$ \\ ${ }^{1}$ New Mind Brain Health Centre, Kuala Lumpur, Malaysia \\ ${ }^{2}$ Department of Psychology, Faculty of Social Sciences and Liberal Arts, UCSI University, Kuala Lumpur, Malaysia \\ ${ }^{3}$ Department of Education, Faculty of Social Sciences and Liberal Arts, UCSI University, Kuala Lumpur, Malaysia
}

\begin{abstract}
Article Info
\section{Article history:}

Received Jul 29, 2021

Revised Nov 9, 2021

Accepted Nov 22, 2021

\section{Keywords:}

Content of sharenting

Motivation for sharenting

Sharenting

Social media

Thematic analysis

ABSTRACT

With social media having penetrated people's daily life, sharenting has become a common phenomenon among the current generation. The term "sharenting" is derived from the combination of the words "share" and "parenting" which refers to parents who often post or share their children's photos/videos on social media such as Facebook, Instagram, Snapchat, YouTube, Blog, and so on. Sharenting has resulted in a lot of consequences due to the sharing of children's information. To understand the consequences of sharenting, the current research analysed the contents of children's information that are shared by parents in Malaysia. The research also investigated the reasons that motivated parents to be involved in the trend of sharenting. A qualitative research adopting one-to-one interview was conducted to obtain in-depth information and knowledge from the respondents selected through a non-probability snowball sampling method. The responses from the interviews were analysed using a thematic analysis where it was noted that in terms of the content shared, two key themes emerged specifically funny and interesting photos as well as children's educational progress. On the other hand, in terms of reasons for sharenting, the respondents listed several reasons including to keep in touch with friends/family members, to keep as memories, and gain support from others.
\end{abstract}

This is an open access article under the CC BY-SA license.

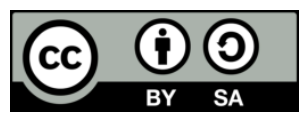

Corresponding Author:

Crendy Tan Yen Teng

Department of Psychology, Faculty of Social Sciences and Liberal Arts, UCSI University

Jalan Puncak Menara Gading, Taman Connaught, 56000 Cheras, Kuala Lumpur, Malaysia

Email: tanyt@ucsiuniversity.edu.my

\section{INTRODUCTION}

In the 21st century, social media has penetrated the everyday life of many people. The number of social media users has increased tremendously to more than a million users around the world [1]. Past study has found that millennials are having the highest addiction rate in using electronic gadgets and services [2]. Previous statistic shows that not only young adults, the percentage of senior citizens who are using social media has also increased to $35 \%$ nowadays compared with the year 2005 [3].

As social media has penetrated our daily life, taking photos, and sharing online has become a daily routine in many people's lives [4]. Although social media brings a lot of benefits to society such as enhancing the relationship of friends and family members who stay apart, it has also brought along some negative effects on people. It is advocated that overusing social media may cause physical and mental health problems on internet users [5]. The increase in the rate of social media usage has impacted people for they are easily affected by the information shared. For example, people may compare themselves with online celebrities to improve their self-image so that they are able to follow the trend. It is generally concurred that 
self-identity is affected by social media, for example, Elsayed [6] claims that social media has negative effects on social identity of adolescents. Further, according to past researches, teenagers, and adults who overuse social media have experienced negatives outcomes such as depression and lack of self-esteem [7], [8]. As such, it can be concurred that social media plays an important role in shaping people's perceptions in the 21 st century.

The term "sharenting" is formed from the words "share" and "parenting" which refers to parents who often post or share their children's photos/videos on social media such as Facebook, Instagram, Snapchat, YouTube, Blog, and so on [9]. Social media users like to share their daily life on Facebook, Instagram, and other applications as well. The term "sharenting" has found a stronghold in the 21st century. As defined by Blum-Ross and Livingstone [10], sharenting is a shorthand term that refers to parents who share and expose their children's information online. According to a previous study, sharenting is considered as a form of intensive parenting [10], [11]. The term has also been said to be a description of the parents who share their children's daily live on social media [12]. Sharenting practices among parents has become a common phenomenon today. McDaniel et al. [13] claims that parents share their children information to stay connected with the world. Besides, parents also try to gain social support and get confirmation on their parenting skills through sharenting [14]. However, in addition to influencing a child's development, sharenting without informing or getting permission from children also raises the question on breaching children's privacy rights [15].

As the phenomena of sharing information of children on social media is growing rapidly, it is noted that this trend has an impact on parenting practices and it also affects children's lives. Despite parents sharing and exposing their children's photos to gain community support from online social media, it must be concurred that children's self-identity is affected when the parents share their personal information. According to Leckart [16], there is a potential effect on children's psychology and identity. Sharenting is a new trend that is difficult to control. However, there are a lot of parents who are still unaware of this issue which is getting worse among the current generation. When social media penetrated the daily lives of people, individuals tend to spend most of their leisure time on scrolling social media posts and feeds. Past research has shown that people are using social media as a communication tool to enhance interpersonal relationships [17]. Past research has also found that men are using social media so that they do not feel lonely while women are using it to enhance their interpersonal relationships [18]. Today, people are too involved in the trend that they are unaware of how frequent they check their social media daily. In line with this, Andrews et al. [19] has mentioned that people lack awareness on the number of times that they check social media on their phone in a day. Here, it must be noted that if people continue overusing social media without any control, it might lead to social media addiction.

As sharenting has become a common act among social media users, parents tend to expose their children on social media without any sense of the danger which leads to unwanted consequences. People reveal personal information of children to data brokers or surveillant authorities [20]. There are some people who misuse the photos and identity of the children that are uploaded by parents which leads to digital kidnapping. 'Digital kidnapping' refers to a stranger who steals a child's photos and reposts them on their own social media platforms [21]. They use those photos to cause a whole new identity of a child and infiltrate other children's lives. This action had caused serious criminal issues which people should not ignore. This is a serious issue with the number of social media users increasing without control. Zuckerberg has mentioned there are more than 175 million people registered as Facebook users all around the world [18]. With such as large number, parents who perform sharenting without due care create more opportunities for digital kidnapping. Hence, this issue should be taken seriously before it gets worst. Many unwarranted incidents have happened before, for example, a private Facebook group has been resharing photos of children with disabilities taken from social media and are making fun of them [22].

There are a lot of negative implications if parents do not practice sharenting wisely. According to a previous research, it highlighted that $55 \%$ of parents share and expose embarrassing information of their children on social media and this affects the children's development of self-identity [23]. Sharenting causes children to face problems in building their own identity during adolescence as their parents had created an online identity for them [24]. Parents might form an online digital identity for their children when they overshare their children's details on social media [25]. With reference to a research conducted in 2010, children can gain an online identity at an average age of six months old [26]. When parents form an online identity for their children, it will cause an interface when children try to develop and form their own selfidentity [27]. Besides, the children are also exposed to negative comments made by society, and this will lower their self-esteem and self-respect [28]. Parents should take responsibilities when forming children's identities and protect their children from harm when they share their children's photos on social media [29]. Further, as highlighted, children's rights are threatened due to the trend of sharenting. According to Steinberg [30], when parents adopt sharenting, it forms a conflict between children's rights and parents' right. This is because when parents share children's information without filtering, it will cause children to face 
embarrassment and discomfort. It might lead to the children having low self-esteem and becoming exposed to online bullying or real physical bullying. Past research has found that there are some children who have been bullied by their friends because their parents had disclosed embarrassing photos of them on social media [30]. An 18 years old girl from Austria sued her parents for sharing more than five hundred of her photos on social media without her consent [31]. Another research [32] also found that $13 \%$ of children are facing a sense of embarrassment when their pictures are shared by their parents on social media.

Today, the content shared by parents on social media are of concern to both parents and the wider public [10]. Parents, as we are aware, usually share their experiences with their children on social media. A study conducted by the University of Michigan showed that parents are mostly sharing their children's information, including photos/videos of their children sleeping, eating, being disciplined, and their day-care or preschool life [30]. It has been highlighted that parents who are into sharenting gain a lot of benefits when they post their children's information on social media. Most parents admit that they are seeking emotional support through sharenting [33]. Though sharenting, parents may also receive praises from friends which boosts their self-esteem as being a good mother/father [34]. Besides, past research has also found that most new mothers are more likely to share their babies' photos until their kids turn two years old [13]. Parents tends to share cute and funny photos of their child instead of sharing naked photo on social media [35]. Some mothers share photos/videos on social media to exchange information of motherhood experience or give advice to other parents who are facing similar conditions with their kids such as hand, foot, and mouth diseases or chickenpox [36].

Further, as reported in the research conducted by the University of Michigan Health System [23], $27 \%$ of the parents who took part in their research had mentioned that they had shared inappropriate photos of their children before. In line with the issues that arise due to inappropriate sharing, some countries have enacted laws to address issues related to sharenting. For example, the government of France has enacted a law to address the negative issues that are resulting from sharenting. Under this law, adult children are given the right to sue their parents if their parents had posted content that violates their rights without their consent [37]. A case happened in year 2017, where a Canadian child sued his parents because his parents had shared his photos as a baby on social media without his permission [38]. This case illustrates evidence that governments in all countries should pay more attention on children's rights and privacy issues. Although the government of France has raised this issue, there are still a lot of countries which have not addressed the concerns related to sharenting and children's rights. For instance, most of the countries including Poland does not have any policy to make sure children's rights are defended from the trend of sharenting [32], [35].

With the increasing use of social media, sharenting has become a new social phenomenon that is common in Malaysia.This behaviour has become the new vogue among parents in Malaysia. Past researchers claim that sharenting influences children's identity development due to mediated representations through networked communication and persistence online via social media [39]. Previous research such as Brosch [40] has only focused on the types of information and the causes of sharenting behaviour. Other research have also discussed the factors that motivates parents to become involved in sharenting behaviour [4]. However, there is a dearth of literature in the Malaysian context. To obtain more details on the sharenting trend in Malaysia, the current research focuses on studying the content and reasons that leads to the sharenting behaviour among them. The concern over the issues related to sharenting including criminal offenses has awoken the world on the dangers surrounding the trend of sharenting especially in the Western countries where changes in the law has occurred in some countries as discussed. Although in Malaysia, the problem has not become critical, this research is significant because besides identifying the content that parents show to the public through sharenting and their reasons for doing it, the findings can help policy makers such as the Malaysian communications and multimedia commission (MCMC) to come out with a policy to restrict posts that are shared on social media which lead to negative consequences. For example, the government could implement a policy where parents who overshare their children's photos/videos are fined if it leads to a breach of children privacy as advocated in Malaysia's Child Act 2001. This is to protect the rights of the children where the welfare of the child is given predominance.

For the purpose of this research, the conceptual definition of sharenting refers to the parents who share information about themselves and their children through online, which is of concern for both parents and the public [10]. The operational definition of sharenting refers to parents' behaviour in posting their children's photos/videos on social media including Facebook, Instagram, and YouTube. On the other hand, the conceptual definition of social media content refers to everything that is included in a collection and that is held or included in something while the operational definition refers to the photos/videos and captions that are posted or shared by parents on social media. 


\section{RESEARCH METHOD}

This section discusses the research method, data collection method, sampling method, and sample size of the study. Further, the instrument used in the study, the inclusion criteria, data collection process and data analysis are also explained. The current study used a qualitative research method where interviews were conducted to understand the nature of the contents shared by Malaysian parents and the reasons that motivated them to do so. The purpose of using this design was to collect in-depth information on the personal experiences of the interview respondents. This was done by conducting one-to-one interviews where the researchers had the opportunity to observe not only non-verbal cues such as body language, eye contact, but also emotional changes reflected by facial expressions and nuances which helped in interpreting the respondents feelings [41]. It also helped the researchers to gain a deeper understanding on the phenomena of sharenting. By using a phenomenological approach, the researchers obtained a deeper understanding on reallife experiences of the interview respondents.

This research was conducted in Kuala Lumpur, Malaysia. Kuala Lumpur is the federal capital city and has the highest population density in Malaysia compared to other cities. According to the Department of Statistic Malaysia, Kuala Lumpur has a total of 7.7 million population in year 2019 comprising of different races such as Malays, Chinese, Indians, Eurasians, Kadazans, Ibans, and indigenous peoples from East Malaysia [42]. With a high density of population, the researchers could easily gain access to participants of different races. Besides, the people living in Kuala Lumpur have a higher socio-economic status compared to other states. According to past research, people with higher socio-economic status tend to spend more time on using social media [43].

The researchers used a non-probability sampling method where respondents were selected by way of snowball sampling. Snowball sampling technique, also known as chain sampling is a kind of nonprobability sampling method which relies on a participant to recruit other participants [44]. Sample size plays an important role in conducting qualitative research [45]. Past research has mentioned that for qualitative research, the sample size must be large enough to make sure that the findings from the respondents cover the researchers' objectives [46]. As the current research used a phenomenological approach, eight respondents from Kuala Lumpur, Malaysia were targeted. According to Creswell [47], at least five to 25 respondents must be recruited in a qualitative research study.

A number of inclusive criteria was set. Firstly, the respondents must be of Malaysian nationality to ensure the consistency of the recruited respondents as this study attempts to study the intention and motivation of sharenting among Malaysian parents. Besides, the respondents should be able to speak, read and listen to English proficiently. This is to ensure that the respondents fully understand the topic and the goals of the current research so that they are able to provide meaningful information during the interview sessions In addition, the respondents selected by the researchers were in the age range of eighteen to forty years old. The reason for setting an age range is because previous studies had highlighted that young adults and adults are more prone to using social media compared to senior citizens [3]. Furthermore, the respondents must be either a father or mother who has at least one child.. The interview sessions were conducted for fifteen to thirty minutes. This is because past research has indicated that the participants lose interest if the interview sessions are too long [48].

The researchers adopted a set of interview questions from Marasli et al. [24]. Since the questionnaire adopted was designed for a quantitative survey method, the researchers modified some of the close-ended questions, so it could fit into the qualitative method adopted in this study. Table 1 shows the comparison of the items adopted and modified.

Table 1. Item comparison between original and modified version of interview questions

\begin{tabular}{ll}
\hline & \\
\hline
\end{tabular}

A pilot test was conducted before the actual interview sessions. This was to identify the flaws, weaknesses and limitations of the modified interview questions. This study adopted the Social Learning 
Theory proposed by Bandura [49]. He believed that people's behaviour is learned from the environment through the process of observational learning [49]. He combines cognitive learning theory and behavioural learning theory in the social learning theory approach. There are three major concepts in the social learning theory. Firstly, people can learn a behaviour through observation. Second, Bandura believe that internal mental states are an essential part of this process and lastly the theory recognized that something can been learned, but it doesn't mean that it will result in a change in behaviour [50]. As discussed, according to the social learning theory, people tend to learn a behaviour through observation [49] and this research is based on the premise that parents observe how other people besides them share their children's photos/videos on social media and try to do the same. Observing the trend of sharenting on social media, parents pick up the skills to also share their children's photos/videos.

\section{RESULTS}

The findings from the interviews revealed two core themes in terms of content; sharing funny and interesting videos, as well as sharing the development of their children's educational process while in terms of reasons for sharenting, three main themes emerged; to keep record as memories, keeping in touch with friends and family, and to gain support from others. These themes are elaborated with actual responses from the interviewees in the following discussion.

The respondents mentioned that most of the photos/videos posted on social media comprised of funny and interesting incidents in their children's life. Most of them believed that sharing their children's funny photos spreads positive thoughts on social media. One of the respondents claimed that a child's life is simpler than an adult's. She believed that through sharing funny photos, she can spread positive vibes to her friends who are also social media users. Her response is as:

"The other reason on posting children pictures and videos on social media is to show the other faces of children. Or is talking about the other faces of human. Cause I feel that children are simpler. Kids don't bring their problems to other days, they will just forget on the day, which is totally different with adults. We adults are more complicated." (Respondent C)

Another respondent claimed that she likes to post her child's photos which are funny on social media to share the joy she gained in that experience. Her response is as:

"Most of the pictures that I posted were hanging out with my children or when they had some funny behaviour. For example, like my daughter drew her father, mother and her on my wall. I was angry but somehow feel warm and funny together. During this moment, I will take down the photos and share on social media." (Respondent F)

Respondent $\mathrm{G}$ also commented that she likes to share photos of her children which are attractive and appealing.

"Of course show others regarding to my children and also what I post actually is those

I think very cute and also is can attract attention from others." (Respondent G)

Beside sharing funny photos, the respondents also stated that they like to share information of their children's progress in their lives. Respondent C's quote shows this clearly.

"Yes, the happier side or their learning and development process. Those things that are providing positive vibes. To share it for other people. I won't share any negative post on social media." (Respondent C)

A few respondents claimed they like to share the development and learning process of their children on social media to share their sense of pride in their children's achievements which they can recollect later. Respondent F's quote shows this:

"Most of the pictures that I posted were hanging out with my children or when they had some funny behaviour. For exampfe, like my daughter draw her father, mother and her on my wall. I was angry but somehow feel warm and funny together. During this moment, I will take down the photos and share on social media." (Respondent F)

Int J Public Health Sci, Vol. 11, No. 1, March 2022: 310-319 
In terms of reasons as to why they take part in sharenting, the respondents claimed that it was to retain memories of time spent with their children. Among the eight respondents in the current research, four of them claimed that they post their children's photos/videos on social media to keep as memories. This is because both Facebook and Instagram have functions to track users' memories of a few years back on a particular day. The quotes from Respondent $\mathrm{H}$ and Respondent $\mathrm{E}$ indicate this clearly:

"I did not share much on it. But when I shared, I want to keep it as a memories. I could be memory when we travel together, memory when both of my son and daughter are playing or laughing. It could be anything la. As long as I33 will miss the moment after I look back to the photos. " (Respondent $\mathrm{H}$ )

"As I mentioned before, I would like to share those memorable photos for example when we are having family trip, I will snap my children photos and post it on social media. This is also convenience to myself to keep as a memory." (Respondent E)

Another reason given by the respondents for their habit of sharenting is that they use the social media as a tool of communication. Half of the respondents claimed that they are using social media to keep in touch with other people such as their family members and friends. They tend to discuss their children issues or daily lives through social media. Another respondent mentioned that when she has no time to contact her friends face-to-face, she will go through their social media and get updates on their status. This is because her friends will update their current life happenings on social media, hence it is the easiest way to know more about her friend's current situation. The responses of Respondent G and Respondent F show this:

"And of course, those social media are very crucial like when we are working, we need to share some information regarding to our workplace and also is a communication platform among others agent." (Respondent G)

"I use social media to keep contact with my friends. This is because I rarely meet my friend after I married. So, I will use social media to knows about my friends' current situation by posting photos of their children or their daily lives. Some of them will also share their current mood by posting some words on social media. Hence, I can know more about them through social media." (Respondent F)

The respondents also claimed that they are involved in sharenting activities to attract attention as well as gain support from other parents. Two out of the eight respondents mentioned that they post their children's photos/videos on social media to attract attention from other people. One of the respondents claimed that it is easier to get interest from agencies or entertainment companies through sharenting because her daughter is keen in modelling. The responses of Respondent A and Respondent G clearly indicates these reasons:

"Like what I said just now, is to gain the... because they are fashion show model, as a advertisement. So basically, is to get the interested and agency to contact us for casting or for any kids job." (Respondent A)

"Of course show others regarding to my children and also what I post actually is those I think very cute and also is can attract attention from others." (Respondent G)

Another respondent, Respondent C claimed that she shared her children's information to gain moral support and advice from other parents and friends. Her statement clearly indicates this:

"One of the reasons is that I can share my children post or status with other parents on social media to discuss on our children issues. For example, like when my children is getting fever, what should I do or sharing recipe on dishes that are good fit children health and development. I do join those mummy group on FB (Facebook) to share our children too." (Respondent C)

Thus, it can be concluded that the respondents habit of sharenting is clearly motivated by their desires to be in close contact with their friends despite their busy schedules, and to also obtain the necessary assistance in times of needs. 


\section{DISCUSSION}

The eight respondents interviewed indicated that they had some understanding and knowledge on the consequences of sharenting. According to the report "Parents, privacy and technology use" which was published on November 2015, $20 \%$ of the content of sharenting included content that makes their children feel embarrassed and uncomfortable [40]. However, the findings in the current study contradicts this. The eight respondents in the current research mentioned that most of the content that they posted were photos on travelling or unforgettable moments such as the first time their babies started to talk or walk. The respondents claimed that they preferred to share positive vibes through social media, and they avoid sharing negative thoughts and negative content. They said that they also posted photos/videos of their children revealing their educational progress be it at the nursery or school.

Most of the respondents mentioned that their friends and family also share their children's information on social media. Their responses clearly indicated that sharenting has become a new trend in Malaysia in recent years. Although it might not be the main reason, but environmental factors such as peer pressure does unconsciously prompt parents to share their children's photos/videos on social media so that they are able to meet society's expectation. Through sharing their children's photos/videos online, the parents claimed that they could also discuss with each other on their children's issues through commenting on the posts. When they are interacting with others on social media, parents feel they are being endorsed as caring parents. Subramanian [51] has mentioned that people are interacting through social media to gain a sense of fulfilment on their social needs.

In addition, most of the respondents claimed that they were busy with their daily lives and this leads them to use the social media as a convenience tool to communication. The findings from the interviews clearly showed that all of the respondents are in consensus as to the reasons for using social media. By scrolling posts that have been shared by other people, the respondents said that they are able to be on track with others and it decreases the feeling of being left out. This confirms Bandura's social learning theory that people learn a behaviour through observation [52]. Past research has proved that social media is becoming a mainstream trend in human life for sharing knowledge [53]. Social media represents a substantial source of knowledge and information in the world of technologies [54]. Sharing children's information is not the only main reason for respondents to use social media. The respondents in the current research mentioned that another reason for using social media is to get the latest news and gain knowledge. Besides gaining knowledge and getting latest news about what is occurring in society, some of the respondents see social media as a communication platform to keep in touch with other people. Two of the respondents mentioned that they are using social media to interact with workplace agencies. For example, one of the respondent's daughters are fashion models. Hence, the respondent said that she will keep updating her daughters' photos/videos to attract entertainment companies or agencies to gain opportunities for her daughters. The other respondent mentioned that due to her workplace demand, she needs to use social media to share information which is part of her job requirement. So, as stated by Baruah [55], social media plays an important role as a platform for users to share information with each other.

Lastly, all eight of the respondents mentioned that they use Facebook and Instagram as the major platforms for sharenting. It shows that both of these social media applications have become noticeable and recognisable platforms in modern culture [56]. From the interview findings, it can be noted that the respondents started to use Instagram for sharenting over a longer period compared to Facebook. According to Salomon [57], Instagram is considered as a mobile application which allows users to take photos/videos from mobile phones and directly upload them on social network and record them as memories that they can recollect anytime. As far back in 2013, Instagram was reported to have 130 million active users around the world and today, Instagram has gained a high unimaginable level of popularity in the world [58].

The objectives of the current research were to find out the content that Malaysian parents share about their children on social media and their reasons for sharing. The research also identified that sometimes, when parents feel frustrated with their children's action, they post photos/videos to share their frustration and to gain support from other parents. However, unconsciously, this behaviour can increase the chances of their children being bullied in school or face other unwarranted consequences. By exposing too much of children's information on social media, parents are placing their children in a dangerous context. Hence, parents should take responsibility when they post their children's photos/videos on social media. As such, Malaysia communication and multimedia commission (MCMC) should enact an Act to restrict what is posted on social media by parents. The researchers are of the opinion that such an Act can reduce crimes related to online sharenting such as digital kidnapping and cyberbullying.

It must be noted at this point that the findings from this research cannot be generalised to represent the population in Malaysia as the sample is very small. Thus, it is advocated for future researchers to increase the sample size to include respondents from the different states in Malaysia. Further, the researchers also recommend future researches to explore the effect of sharenting on children's privacy issues. According to 
past research, the issues of parents' infringing children's rights to privacy has become a problem and is increasing in recent years [15].

\section{CONCLUSION}

As a conclusion, it can be said that today, parents are raising children in a "digitalised culture" which is causing them to face new and unique parenting problems compared to parents in previous generations. Facebook, Instagram, and other such social media applications are seen as easy platforms to share the joys and challenges of parenthood. This trend of sharenting documents of children's lives publicly with increasing frequency has become a social norm. Consequently, many children have a plethora of pictures, posts, and updates about their lives on social media before they can even walk. The current study has provided an overview of the contents shared on social media by Malaysian parents and their motivation for sharing. In addition, this initial study also shows that Malaysian parents are not overtly concerned with the negative consequences of sharenting which has started to hit the western countries. They are still unaware of the debate surrounding the issue of sharenting in terms of parents' rights and the children's rights. According to recent research, parents are seen as the gatekeepers of the personal information of the children and as such they should be able to decide and control what and how much information can be safely shared and disclosed to the public while balancing their personal gain and right to share with the children's safety and right to privacy. Thus, it is suggested that this issue of sharenting should be further analyzed and an effective legal framework should be implemented in Malaysia to control this practice before the crimes revolving around sharenting such as digital kidnapping and cyber bullying becomes an issue in our country as the saying goes 'to prevent is better than to cure'.

\section{REFERENCES}

[1] S. Thanuskodi, "Usage of social media among LIS students in India," in Literacy Skill Development for Library Science Professionals, 2019, pp. 1-24.

[2] M. M. Singh, M. Amiri, and S. Sabbarwal, "Social media usage: positive and negative effects on the life style of Indian youth," Iranian Journal of Social Sciences and Humanities Research, vol. 5, no. 3, pp. 123-127, 2017, [Online]. Available: http://uctjournals.com.

[3] A. Perrin, "Social media usage: 2005-2015," Pew Research Center, 2015. https://www.secretintelligenceservice.org/wpcontent/uploads/2016/02/PI_2015-10-08_Social-Networking-Usage-2005-2015_FINAL.pdf (accessed Jul. 23, 2021).

[4] A. Wagner and L. A. Gasche, "Sharenting: making decisions about other's privacy on social networking sites," Publications of Darmstadt Technical University, Institute for Business Studies (BWL), 2018.

[5] I. Pantic, "Online social networking and mental health," Cyberpsychology, Behavior and Social Networking, vol. 17, no. 10, pp. 652-657, Oct. 2014, doi: 10.1089/cyber.2014.0070.

[6] W. Elsayed, "The negative effects of social media on the social identity of adolescents from the perspective of social work," Heliyon, vol. 7, no. 2, p. e06327, Feb. 2021, doi: 10.1016/j.heliyon.2021.e06327.

[7] Y. Alfasi, "The grass is always greener on my friends' profiles: the effect of Facebook social comparison on state self-esteem and depression," Personality and Individual Differences, vol. 147, pp. 111-117, Sep. 2019, doi: 10.1016/j.paid.2019.04.032.

[8] P. Ozimek and H. W. Bierhoff, "All my online-friends are better than me-three studies about ability-based comparative social media use, self-esteem, and depressive tendencies," Behaviour and Information Technology, vol. 39, no. 10, pp. 1110-1123, Oct. 2020, doi: 10.1080/0144929X.2019.1642385.

[9] A. Brosch, "Sharenting - why do parents violate their children's privacy?," New Educational Review, vol. 54, no. 4, pp. 75-85, Dec. 2018, doi: 10.15804/tner.2018.54.4.06.

[10] A. Blum-Ross and S. Livingstone, "Sharenting,' parent blogging, and the boundaries of the digital self," Popular Communication, vol. 15, no. 2, pp. 110-125, Apr. 2017, doi: 10.1080/15405702.2016.1223300.

[11] C. Faircloth, "Intensive parenting and the expansion of parenting," in Parenting Culture Studies, London: Palgrave Macmillan UK, 2014, pp. 25-50.

[12] S. Hays, The cultural contradictions of motherhood. New Haven, CT: Yale University Press, 1996.

[13] B. T. McDaniel, S. M. Coyne, and E. K. Holmes, "New mothers and media use: associations between blogging, social networking, and maternal well-being," Maternal and Child Health Journal, vol. 16, no. 7, pp. 1509-1517, Oct. 2012, doi: 10.1007/s10995-011-0918-2.

[14] M. R. Morris, "Social networking site use by mothers of young children," in Proceedings of the ACM Conference on Computer Supported Cooperative Work, CSCW, Feb. 2014, pp. 1272-1282, doi: 10.1145/2531602.2531603.

[15] Siibak, Andra, and Keily Traks. "The Dark Sides of Sharenting." Catalan Journal of Communication \& Cultural Studies, vol. 11, no. 1, 2019, pp. 115-121., doi: 10.1386/cjes.11.1.115_1

[16] S. Leckart, "The Facebook-free baby: are you a mom or dad who's guilty of 'oversharenting'? The cure may be to not share at all,” 2012. https://www.wsj.com/articles/SB10001424052702304451104577392041180138910 (accessed Jul. 23, 2021).

[17] K. Subrahmanyam and P. Greenfield, "Online communication and adolescent relationships," Future of Children, vol. 18, no. 1, pp. 119-146, 2008, doi: 10.1353/foc.0.0006.

[18] J. Cabral, "Is generation Y addicted to social media?," The Elon Journal of Undergraduate Research in Communications, vol. 2, pp. 59-68, 2011, Accessed: Jul. 27, 2021. [Online]. Available: https://www.elon.edu/u/academics/communications/journal/wpcontent/uploads/sites/153/2017/06/01Cabral.pdf.

[19] S. Andrews, D. A. Ellis, H. Shaw, and L. Piwek, "Beyond self-report: tools to compare estimated and real-world smartphone use," PLOS ONE, vol. 10, no. 10, p. e0139004, Oct. 2015, doi: 10.1371/journal.pone.0139004.

[20] T. Minkus, K. Liu, and K. W. Ross, "Children seen but not heard: when parents compromise children's online privacy," in $W W W$ 2015 - Proceedings of the 24th International Conference on World Wide Web, May 2015, pp. 776-786, doi: 
$10.1145 / 2736277.2741124$.

[21] Haley, K, "Sharenting and the (Potential) Right to be Forgotten," Indiana Law Journal, vol 95 no. 3, pp. 1005-1020, 2020 https://www.repository.law.indiana.edu/ilj/vol95/iss3/9.

[22] T. Parker, "Mean moms bash 'ugly' toddlers in secret Facebook group," 2013. https://au.news.yahoo.com/mean-mothers-bashugly-babies-in-secret-facebook-group-19741277.html (accessed Jul. 23, 2021).

[23] University of Michigan Health System, "Sharenting' trends: do parents share too much about their kids on social media?," ScienceDaily, 2015. www.sciencedaily.com/releases/2015/03/150316092805.htm (accessed Jul. 23, 2021).

[24] M. Marasli, E. Sühendan, N. H. Yilmazturk, and F. Cok, "Parents' shares on social networking sites about their children: sharenting," Anthropologist, vol. 24, no. 2, pp. 399-406, May 2016, doi: 10.1080/09720073.2016.11892031.

[25] G. Y. Choi and J. Lewallen, "Say Instagram, kids!': examining sharenting and children's digital representations on Instagram," Howard Journal of Communications, vol. 29, no. 2, pp. 140-160, Apr. 2018, doi: 10.1080/10646175.2017.1327380.

[26] J. Brand and R. Renner, "Digital birth research, results, and reflections for parents of children zero to two," AVG Technologies Digital Diaries, 2010. http://www.avgdigitaldiaries.com/post/6874613434/digital-birth-research-results-andreflections (accessed Jul. 23, 2021)

[27] S. Smith, "Are you guilty of oversharenting?," The Sydney Morning Herald, 2013. https://www.smh.com.au/lifestyle/are-youguilty-of-oversharenting-20130701-2p74h.html (accessed Jul. 23, 2021).

[28] C. Jones, "Are you guilty of 'oversharenting'? Why we owe our kids online privacy," TIME, 2013. https://healthland.time.com/2013/02/01/are-you-guilty-of-oversharenting-why-we-owe-our-kids-online-privacy/ (accessed Jul. 23, 2021).

[29] N. J. King and V. T. Raja, "Protecting the privacy and security of sensitive customer data in the cloud," Computer Law and Security Review, vol. 28, no. 3, pp. 308-319, Jun. 2012, doi: 10.1016/j.clsr.2012.03.003.

[30] S. B. Steinberg, "Sharenting: children's privacy in the age of social media," Emory Law Journal, vol. 66, p. 839, 2017, Accessed: Jul. 23, 2021. [Online]. Available: https://scholarship.law.ufl.edu/cgi/viewcontent.cgi?article=1796\&context=facultypub.

[31] A. May, "18-year-old sues parents for posting baby pictures on Facebook," USA Today, 2016. https://eu.usatoday.com/story/news/nation-now/2016/09/16/18-year-old-sues-parents-posting-baby-pictures-facebook/90479402/ (accessed Jul. 23, 2021).

[32] Hart Research Associates, "Parents, privacy \& technology use," Family Online Safety Institute, 2015. https://www.fosi.org/policy-research/parents-privacy-technology-use (accessed Jul. 23, 2021).

[33] J. Lee and S. Clark, "Parenting \& 'sharenting': the opportunities and risks of parenting in the social media age," Institute for Healthcare Policy \& Innovation, 2015. https://ihpi.umich.edu/news/parenting-“sharenting”-opportunities-risks-parenting-socialmedia-age (accessed Jul. 23, 2021).

[34] H. Krasnova, S. Spiekermann, K. Koroleva, and T. Hildebrand, "Online social networks: why we disclose," Journal of Information Technology, vol. 25, no. 2, pp. 109-125, Jun. 2010, doi: 10.1057/jit.2010.6.

[35] P. Kumar and S. Schoenebeck, "The modern day baby book: enacting good mothering and stewarding privacy on Facebook," in Proceedings of the 18th ACM Conference on Computer Supported Cooperative Work \& Social Computing, Feb. 2015, pp. 13021312, doi: 10.1145/2675133.2675149.

[36] S. Pettigrew, C. Archer, and P. Harrigan, "A thematic analysis of mothers' motivations for blogging," Maternal and Child Health Journal, vol. 20, no. 5, pp. 1025-1031, May 2016, doi: 10.1007/s10995-015-1887-7.

[37] D. Chazan, "French parents 'could be jailed' for posting children's photos online - Telegraph," The Telegraph, 2016. http://www.telegraph.co.uk/news/worldnews/europe/france/12179584/French-parents-could-be-jailed-for-posting-childrensphotos-online.html (accessed Jul. 23, 2021).

[38] CBC Radio, "Child sues parents for posting 'embarrassing' baby pictures on social media," CBC Comedy, 2017. http://www.cbc.ca/radio/thisisthat/selfie-kid-graffiti-counselor-golf-course-accidental-pianist-1.3811185/child-sues-parents-forposting-embarrassing-baby-pictures-on-social-media-1.3811188 (accessed Jul. 23, 2021).

[39] N. Davidson-Wall, “Mum, seriously!': sharenting the new social trend with no opt-out." in Paper presented at the 9th Debating Communities and Social Networks 2018 OUA Conference. Online Conference, 2018, pp. 1-11.

[40] A. Brosch, "When the child is born into the internet: sharenting as a growing trend among parents on Facebook," New Educational Review, vol. 43, no. 1, pp. 225-235, Mar. 2016, doi: 10.15804/tner.2016.43.1.19.

[41] S. D. Lambert and C. G. Loiselle, "Combining individual interviews and focus groups to enhance data richness," Journal of Advanced Nursing, vol. 62, no. 2, pp. 228-237, Apr. 2008, doi: 10.1111/j.1365-2648.2007.04559.x.

[42] “Kuala Lumpur population 2019," World Population Review, 2019. http://worldpopulationreview.com/world-cities/kuala-lumpur/ (accessed Jul. 23, 2021).

[43] A. S. Khan, A. ur Rahman, and L. T. Qazi, "The relationship between internet usage, socioeconomic status, subjective health and social status," Business \& Economic Review, vol. 8, no. Special Edition, pp. 67-82, Oct. 2016, doi: 10.22547/ber/8.se.5.

[44] B. Hancock, E. Ockleford, and K. Windridge, "An introduction to qualitative research." The NIHR RDS for the East Midlands / Yorkshire and the Humber, 2007.

[45] P. DePaulo, "Sample size for qualitative research," 2000. http://www.quirks.com/articles/a2000/20001202.aspx?searchID=383113850 (accessed Jul. 23, 2021).

[46] S. H. Oppong, "The problem of sampling in qualitative research," Asian Journal of Management Sciences and Education, vol. 2, no. 2, pp. 202-210, 2013, Accessed: Jul. 23, 2021. [Online]. Available: http://www.ajmse.leena-luna.co.jp.

[47] J. W. Creswell, Qualitative inquiry and research design: choosing among five traditions. Thousand Oaks, CA: Sage Publications, 1998.

[48] A. G. Fink, How to conduct surveys: a step-by-step guide. Los Angeles: Sage Publications, 2015.

[49] A. Bandura, Social learning theory. Englewood Cliffs, NJ: Prentice Hall, 1977.

[50] K. Cherry, "How social learning theory works," verywell mind, 2018. https://www.verywellmind.com/social-learning-theory2795074 (accessed Jan. 13, 2021).

[51] K. R. Subramanian, "Influence of social media in interpersonal communication," International Journal of Scientific Progress and Research (IJSPR), vol. 38, no. 109, pp. 70-75, 2017.

[52] A. Bandura, "Influence of models' reinforcement contingencies on the acquisition of imitative responses," Journal of Personality and Social Psychology, vol. 1, no. 6, pp. 589-595, Jun. 1965, doi: 10.1037/h0022070.

[53] Z. Gaál, L. Szabó, N. Obermayer-Kovács, and A. Csepregi, "Exploring the role of social media in knowledge sharing," The Electronic Journal of Knowledge Management, vol. 13, no. 3, 2015, Accessed: Jan. 13, 2021. [Online]. Available: file:///C:/Users/user/Downloads/2015art_EJKM_GalSzabOKNCsepregi_KnowledgeSSMedia.pdf.

[54] O. Mauroner, "Social media for the purpose of knowledge creation and creativity management-a study of knowledge workers in 
Germany," International Journal Learning and Intellectual Capital, vol. 13, no. 2-3, pp. 167-183, 2016.

[55] T. D. Baruah, "Effectiveness of social media as a tool of communication and its potential for technology enabled connections: a micro-level study," International Journal of Scientific and Research Publications, vol. 2, no. 5, pp. 1-10, 2012.

[56] L. Lazard, R. Capdevila, C. Dann, A. Locke, and S. Roper, "Sharenting: pride, affect and the day-to-day politics of digital mothering," Social and Personality Psychology Compass, vol. 13, no. 4, p. e12443, Apr. 2019, doi: 10.1111/spc3.12443.

[57] D. Salomon, "Moving on from Facebook: using Instagram to connect with undergraduates and engage in teaching and learning," College and Research Libraries News, vol. 74, no. 8, pp. 408-412, Sep. 2013, doi: 10.5860/crln.74.8.8991.

[58] Omnicore, "Instagram by the numbers: stats, demographics \& fun facts," 2021. https://www.omnicoreagency.com/instagramstatistics/ (accessed Jul. 25, 2021).

\section{BIOGRAPHIES OF AUTHORS}
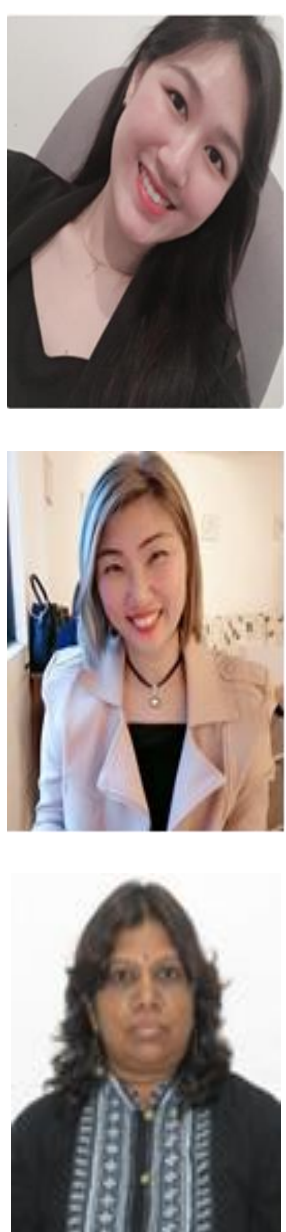

Lee Jia Wen (D) $8 \mathrm{SC}$ P is a psychology degree holder from UCSI University. She has received the clinical neurofeedback practitioner certification from spectrum biofeedback certification institute of Asia (SBCIA) during year 2020 with the accumulated 1000 practicum hours in year 2021. She is now working as a clinical neurofeedback practitioner in New Mind Brain Health Centre. Besides, she is also a registered behavioural technician from behaviour analyst certification board (BACB) since year 2021. With this specification, she is specialized in handling the children's cases with the issues such as ADHD, Autism, learning delay issues, and etc. In addition, she also helps adults with certain cases including depression, anxiety, sleep issues, and PTSD. At the moment, she is dedicated to apply her knowledge to those who are in need while at the same time to gain more practical experience for her further endeavours in her study. She can be contacted at email: jiawen9261@gmail.com.

Crendy Tan Yen Teng (D) $\mathrm{SC}$ $\mathrm{P}$ is the Dean, Faculty of Social Sciences and Liberal Arts, UCSI University. She is also the former Head in the Psychology Department. She had obtained her Ph.D., Psychology of Child Development and Master in Guidance and Counselling. She is a registered counsellor with the Board of Counsellor, Malaysia and engaged as a guest counsellor at The Bridge Communication Sdn. Bhd. Throughout her career, she is actively engaged herself in giving talks/workshops/trainings/webinars to schools, NGOs, and public. Besides, she is also active in conducting research, publish academic papers, and being regular invited speaker for 8TV and AiFm 89.3 Radio Broadcast. She is passionate in conducting research that related to children, parenting, and the family related topics. She can be contacted at email: tanyt@ucsiuniversity.edu.my.

Saroja Dhanapal (iD) SC $\mathrm{P}$ is a veteran in the academic arena. She is currently employed as an Assistant Professor in the Faculty of Social Sciences and Liberal Arts, UCSI University. She has contributed extensively to the academic profession. She has been teaching for the past 36 years in both public and private schools and universities. She started her teaching profession after completing a three years' teachers' training course in Maktab Perguruan Seri Kota, Kuala Lumpur. She obtained a Distinction for her teaching practice. She then pursued and completed her B.A. (HONS.) in English Literature at University of Malaya, M.A (English Literature) at University of Malaya, L.L.B (HONS) at University of London, LLM at University of Malaya, Ph.D. in TESL (Cultivating critical and creative thinking skills through an integrated approach to the teaching of literary texts) at University Putra Malaysia and her second Ph.D. in Law at University Malaya. She obtained a Distinction for her thesis which is on Human Rights Law (Transforming the legal landscape: an initial study of security offences (special measures) act (SOSMA) 2012) that she completed in two years. She also has a wide array of publication in her areas of expertise; English Literature, Education, and Law. She can be contacted at email: saroja.dhanapal07@gmail.com. 